ScIDice

\section{Assessment Of Probiotic Activity and Anti-Oxidant Potential Of Commercially Available Probiotic Chocolate In India}

\section{International Journal of Dentistry and Oral Science (IJDOS) ISSN: 2377-8075}

Research Article

Lalitha Rani Chellappa ${ }^{1}$, Srisakthi Doraikannan ${ }^{1 *}$, Meignana Arumugham Indiran ${ }^{1}$

${ }^{1}$ Department of Public Health Dentistry, Saveetha Dental College, Saveetha Institute of Management and Technical Sciences, No.162, Poonamallee High Road, Chennai 600077, Tamil Nadu, India.

\title{
Abstract
}

Introduction: Chocolate is one of the most commonly consumed product in the world at all age groups. It is socially acceptable by most of the consumers for its taste. If its in the form of a functional food with probiotic activity without altering the taste, it becomes beneficial and can reach a wider population.

Aim: The aim of the study is to assess and compare the antimicrobial and antioxidant activity of commercially available probiotic infused green tea, green coffee and slim tea.

Materials and Methods: Synthesis of probiotic medium is done by 2 gm of each sample was taken in 1 flask of $15 \mathrm{ml}$ peptone water and mixed well. Then it is inoculated in MRS agar plate and it is sealed in an anaerobic jar for 48 hours. Antimicrobial activity is tested by agar well diffusion method against S.mutans and the zone of inhibition is measured. Antioxidant activity is measured with DPPH and \% of inhibition is measured.

Results: In the antimicrobial activity, in all the samples the activity increased with increasing concentration, but the maximum was seen in cranberry orange probiotic chocolate. In antioxidant activity, all the samples showed antioxidant activity although cranberry orange probiotic chocolate showed more antioxidant activity than peanut butter caramel chocolate

Conclusion: In our study, Bacillus coagulans incorporated probiotic chocolate bars exhibited both antimicrobial and antioxidant properties. Since there was a good antimicrobial activity against $S$. mutans, these can be incorporated as a potential antibacterial agent for oral infections and as an antioxidant carrier in the local drug delivery.

Keywords: Probiotic; Chocolate; Antimicrobial Activity; DPPH; Agar Well Diffusion Method; S.mutans.

\section{Introduction}

Chocolate is, in essence, composed of cocoa mass and sugar suspended in a cocoa butter matrix [1]. Major types of chocolates are dark, milk and white that differs in content of cocoa solid, milk fat and cocoa butter in the formulation. Chocolates are semisolid suspensions of fine solid particles of sugar and cocoa (and milk, depending on type); making about $70 \%$ in total, in a continuous fat phase [2]. Chocolate is consumed all over the world, by every age group and every social class. The popularity of this food appears to mainly associate with its potential to arouse sensory pleasure and positive emotions [3]. Foods with positive acceptance have been enriched with compounds that improve consumers health. For example, reducing the fat content in the diet might decrease the energy intake and therefore, contribute to the prevention of obesity. There is an opportunity using indulgent foods, such as chocolate to achieve this aim $[4,5]$.

Functional foods are those that provide basic nutrition and, at the same time, promote health [6]. As the market for functional foods continues to expand, research in the development of food products containing probiotic bacteria also has grown [7]. There are two dietary strategies to increase the beneficial microorganisms in the instestine. The first one is by the consumption of probiotics and the other one is by increasing the number of resident microorganisms in the gut tract, using prebiotics [8]. Probiotics are viable microorganisms that are beneficial to the host when administered in appropriate quantities [9]. They may play an important role in helping the body protect itself from infection, especially along the colonized mucosal surfaces of the gastrointestinal tract

*Corresponding Author:
Dr. Srisakthi Doraikannan,

Department of Public Health Dentistry, Saveetha Dental College, Saveetha Institute of Management and Technical Sciences, No.162, Poonamallee High Road, Chennai 600077,

Tamil Nadu, India.

Tel: + 918122399966

E-mail: drsrisakthiphd@gmail.com

Received: April 02, 2021

Accepted: September 20, 2021

Published: September 21, 2021

Citation: Lalitha Rani Chellappa, Srisakthi Doraikannan, Meignana Arumugham Indiran. Assessment Of Probiotic Activity and Anti-Oxidant Potential Of Commercially Available Probiotic Chocolate In India. Int J Dentistry Oral Sci. 2021;8(9):4393-4398. doi: http://dx.doi.org/10.19070/2377-8075-21000894

Copyright: Dr. Srisakthi Doraikannan 2021. This is an open-access article distributed under the terms of the Creative Commons Attribution License, which permits unrestricted use, distribution and reproduction in any medium, provided the original author and source are credited. 
[10]. Ouwehand, Salminen, and Isolauri affirmed that to be considered a probiotic, the microorganism must have certain properties and functions, like adhesion in the host epithelial tissue, acid resistance and bile tolerance, pathogen elimination or reduction in pathogen adherence, production of acid, hydrogen peroxide and bacteriocin against the growth of pathogens, assurance and improvement of gut microbiota balance [11].

The attention and stress was on the survival in the gut and temporary colonization of gut mucosa surface. The species with beneficial properties belong, generally, to the genera Bifidobacterium and Lactobacillus [12]. Probiotic bacteria including bifidobacterial and lactobacilli and Bacillus coagulans are natural inhibitors of the human intestine. They beneficially affect human health by improving the intestinal microorganisms and $\mathrm{pH}$ balance and the defences against pathogens. Additional health benefits attributed to probiotics are the stimulation of the immune system, blood cholesterol reduction, vitamin synthesis, anti-carcinogenic and anti-bacterial activities [13]. Other crucial criteria to determine the efficacy and the efficiency of the product containing probiotics are the acceptance of the product by the consumers and the survival of probiotic microorganisms during its production. In general, the food industry has applied the recommended level of $106 \mathrm{cfu} g 1$ at the time of consumption for Lactobacillus acidophilus, bifidobacteria and other probiotic bacteria [7].

A prebiotic is a non digestible food ingredient that beneficially affects the human body by selectively stimulating the activity of certain colon bacteria. This means that some dietary compounds are resistant to digestive enzyme and are not absorbed in GIT including small intestine. These compounds when go to large intestine where most of the gut microbiota is present, these stimulate the growth of some beneficial microorganisms in the gut especially bifidobacteria [14]. Inulin is an oligosaccharide which is extracted from plants like onions, asparagus root, Jerusalem artichoke tuber, wheat, banana, Chinese chives, burdock, garlic, honey, oat, pine, rye and chicory [15]. It is officially recognized as a natural food ingredient and is classified as a dietary fibre in most European countries [14]. Studies on humans have shown significant changes in the composition of faecal microbiota, allowing the conclusion that these oligosaccharides are prebiotics [16]. The other physiological and nutritional effects associated with inulin are modulation of calcium absorption and lipid metabolism, and a possible role in reducing the risk of colon precancerous lesion.

The term synbiotic is used when a product contains both probiotic and prebiotic ingredients. The synergism is attained in vivo by the ingestion of lactobacilli and by the promotion of indigenous bifidobacteria simultaneously [17]. For example a product comprising of inulin or oligofructose and probiotic bifidobacteria or L. paracasei, for example, can be considered as a symbiotic. Synbiotic products have not been intensively studied to date. Roberfroid suggested that these ingrediants can improve the survival of bacteria when they pass into the small intestine and produce benefits in the large bowel. It is not known if the individual advantages might be additive or even synergistic [18].

Aerated dairy products have found to have great potential in the market and attracts the customers who are interested in lighter and healthier products [19]. Mousse is an aerated dessert with stabilized foamy structure that is gaining popularity in the market and produced on a large scale. The most popular mousse flavour is chocolate, followed by orange, lemon, cranberry, peanut butter, caramel and strawberry [20]. The large scale production of aerated dairy desserts is delicate, requiring knowledge about the formation and stabilization of foam, the use of functional ingredients (emulsifiers, stabilizers), and the interaction and interference of process parameters in the properties of the resulting product [19]. The aim of this study is to assess the antimicrobial activity and anti-oxidant potential of commercially available probiotic chocolate in India.

\section{Materials and Methods}

Figure 1 shows the preparation of probiotic stains from commercially available probiotic chocolate in two flavours. Peptone water was used for preparation of extract.

Figure 2 shows the picture of anaerobic jar which was used to store the culture plates after inoculation in MRS agar. The plates were stored for 5-7 days in the anaerobic jar for probiotic bacteria growth.

Figure 3 shows the subcultures of subcultures of the probiotic stains inoculated on MRS agar. Subcultures were done thrice for better isolation of the probiotic stains.

Figure 4 shows the supernatant obtained after centrifugation of the samples. The supernatant were used for antimicrobial and antioxidant properties.

Chocolate used: SIRIMIRI protein chocolate bars with probiotics.

Ingredients: Whey protein isolate, fructo-oligosaccharides, dark chocolate (sugar, cocoa solids, lecithin), almond butter, milk protein concentrate, honey, butter, , Jowar millet crisp, rock salt and Bacillus Coagulans.

Chocolate 1: Dried cranberries and orange extract

Figure 1. Preparation of the probiotic extract.
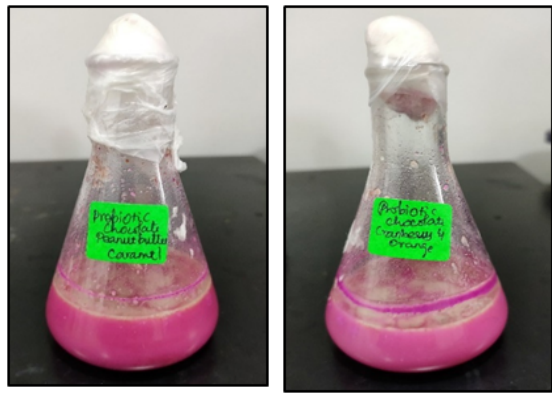
Figure 2. Anaerobic jar.

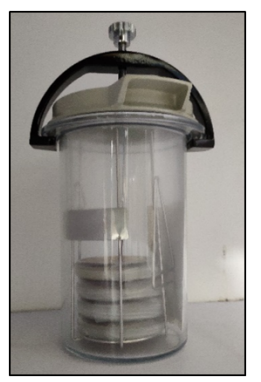

Figure 3. Subcultures of the samples.

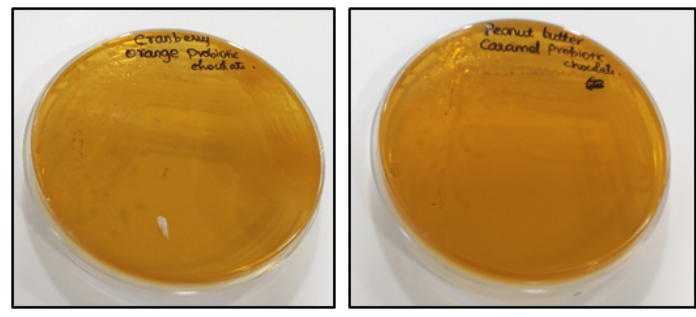

Figure 4. Collection of supernatants after centrifugation.

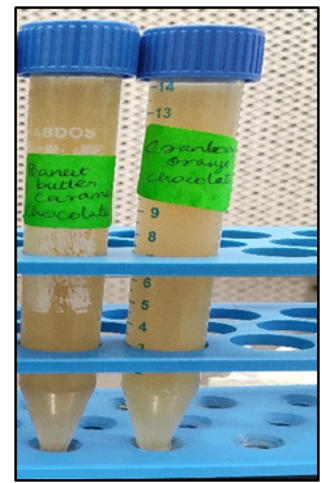

Chocolate 2: Peanuts and caramel extract

Synthesis of probiotic chocolate medium: $5 \mathrm{gm}$ of each chocolate was taken in 2 tubes of $15 \mathrm{~mL}$ peptone water and mixed well. Then it is kept in a shaker at $250 \mathrm{rpm}$ for 24 hours. Then it is inoculated in MRS agar plate and it is sealed in an anaerobic jar for 48 hours.

The culture is sub-cultured thrice and centrifuged and the supernatant was stored for further study.

Antimicrobial activity: Antibacterial activity of the supernatant strains against oral pathogen was determined using the agar-well diffusion method with some modifications of the protocol indicated by Chellappa et al. [30] ( Streptococcus mutans).

The selected LAB isolates were inoculated from slants to fresh MRS broth containing 1\% glucose and incubated overnight at $37^{\circ} \mathrm{C}$ overnight active culture broth of each isolate was centrifuged separately at $5000 \mathrm{rpm}$ for $10 \mathrm{~min}$ at $4^{\circ}$ cell-free supernatant from each separate culture was collected as a crude extract for the antagonistic study against selected oral pathogen. Pure cultures of oral pathogen were inoculated from slants to brain heart infusion broth. After 24 -hour incubation at $37^{\circ} \mathrm{C}$, a volume of $100 \mu \mathrm{L}$ of inoculum of each indicator bacteria was swabbed evenly over the surface of nutrient agar plates with a sterile cotton swab. plates were allowed to dry, and a sterile cork borer (diameter $5 \mathrm{~mm}$ ) was used to cut uniform wells in the agar. Each well was filled with $100 \mu \mathrm{L}$ culture-free filtrate obtained from each of the acid-bile-tolerant LAB isolates. After incubation at $37^{\circ} \mathrm{C}$ for 24 to 48 hours, the plates were observed for a zone of inhibition (ZOI) around the well. )e diameter of the inhibition zone was measured by calipers in millimeters, and a clear zone of $1 \mathrm{~mm}$ or more was considered positive inhibition [31,32]. Experiment was carried out in triplicates, and the activity was reported as the diameter of $\mathrm{ZOI} \pm \mathrm{SD}$.

\section{Antioxidant activity - DPPH assay}

The 2,2-diphenyl-2-picrylhydrazyl hydrate (DPPH) free radical scavenging activity of the chocolate samples was determined to assess its antioxidant potential. Various concentrations (10-50 $\mu \mathrm{g} /$ $\mathrm{ml}$ ) of inoculated culture were mixed with $1 \mathrm{ml}$ of $0.1 \mathrm{mM} \mathrm{DPPH}$ in methanol solution and $450 \mu \mathrm{l}$ of $50 \mathrm{mM}$ Tris- $\mathrm{HCl}$ buffer $(\mathrm{pH}$ 7.4), and incubated for $30 \mathrm{~min}$. After incubation, the reduction in the number of DPPH free radicals was measured based on the absorbance at $517 \mathrm{~nm}$. Ascorbic acid was used as the standard controls and the percent (\%) inhibition was calculated from the following equation:

$\%$ Inhibition $=[$ Absorbance of control-Absorbance of test sample/ Absorbance of control] $\times 100$

\section{Results}

Figure 5 shows the antimicrobial action of probiotic stains against the oral pathogen S. mutans. Agar well diffusion method was used 
to assess the activity with 3 various concentrations of $25 \mu \mathrm{L}, 50$ $\mu \mathrm{L}$, and $100 \mu \mathrm{L}$.

Figure 6 shows the antioxidant activity of peanut butter caramel chocolate using DPPH assay. Various concentrations from $10 \mu \mathrm{L}$ to $50 \mu \mathrm{L}$ were assessed for anti-oxidant potential.

igure 7 shows the antioxidant activity of cranberry orange chocolate using DPPH assay. Various concentrations from $10 \mu \mathrm{L}$ to 50 $\mu \mathrm{L}$ were assessed for anti-oxidant potential.

Graph 1 shows the antibiotic potential of the samples. It shows that in the peanut butter caramel chocolate, $25 \mu \mathrm{L}, 50 \mu \mathrm{L}$ and $100 \mu \mathrm{L}$ showed $9 \mathrm{~nm}, 10 \mathrm{~nm}$ and $13 \mathrm{~nm}$ in the zone of inhibition; in the cranberry orange chocolate, $25 \mu \mathrm{L}, 50 \mu \mathrm{L}$ and $100 \mu \mathrm{L}$ showed $9 \mathrm{~nm}, 12 \mathrm{~nm}$ and $15 \mathrm{~nm}$ in the zone of inhibition although all the samples had increased activity with increasing concentration, but the maximum was seen in cranberry orange probiotic chocolate.

Graph 2 shows the antioxidant activity of the probiotic chocolates. In the peanut butter caramel sample, 13\%,29\%,42\%,55\% and $70 \%$ of inhibition was observed with increasing concentrations of $10 \mu \mathrm{L}, 20 \mu \mathrm{L}, 30 \mu \mathrm{L}, 40 \mu \mathrm{L}$ and $50 \mu \mathrm{L}$ respectively. In the cranberry orange sample, $26 \%, 27 \%, 42 \%, 47 \%$ and $65 \%$ of inhibition was observed with increasing concentrations of $10 \mu \mathrm{L}$, $20 \mu \mathrm{L}, 30 \mu \mathrm{L}, 40 \mu \mathrm{L}$ and $50 \mu \mathrm{L}$ respectively. Although cranberry orange exhibited more anti oxidant activity at low concentration, at higher concentrations, peanut butter caramel had more antioxidant potent.
The growth of the probiotic stains were confirmed by subcultures (figure 3). In the antimicrobial activity, in the peanut butter caramel chocolate, $25 \mu \mathrm{L}, 50 \mu \mathrm{L}$ and $100 \mu \mathrm{L}$ showed $9 \mathrm{~nm}, 10 \mathrm{~nm}$ and $13 \mathrm{~nm}$ in the zone of inhibition; in the cranberry orange chocolate, $25 \mu \mathrm{L}, 50 \mu \mathrm{L}$ and $100 \mu \mathrm{L}$ showed $9 \mathrm{~nm}, 12 \mathrm{~nm}$ and $15 \mathrm{~nm}$ in the zone of inhibition although all the samples had increased activity with increasing concentration, but the maximum was seen in cranberry orange probiotic chocolate (figure 5 and graph 1). In the antioxidant activity of the probiotic chocolates, the peanut butter caramel sample had $13 \%, 29 \%, 42 \%, 55 \%$ and $70 \%$ of inhibition with increasing concentrations of $10 \mu \mathrm{L}, 20 \mu \mathrm{L}, 30 \mu \mathrm{L}, 40$ $\mu \mathrm{L}$ and $50 \mu \mathrm{L}$ respectively. In the cranberry orange sample 2 had $6 \%, 27 \%, 42 \%, 47 \%$ and $65 \%$ of inhibition with increasing concentrations of $10 \mu \mathrm{L}, 20 \mu \mathrm{L}, 30 \mu \mathrm{L}, 40 \mu \mathrm{L}$ and $50 \mu \mathrm{L}$ respectively. Although cranberry orange exhibited more antioxidant activity at low concentration, at higher concentrations, peanut butter caramel had more antioxidant potential (figure 6,7 and graph 2).

\section{Discussion}

Numerous methods have been explored to increase the viability and activity of probiotics in commercial products: selection of acid- and bile-resistant strains, stress adaptation, and incorporation of micronutrients. An alternative solution is represented by microencapsulation in sealed capsules of different materials, which release their content under specific environmental conditions [33]. Among these materials, lipids such as oil emulsions, milk fat and water insoluble microcapsules appear to be of con-

Figure 5. Antimicrobial activity of the samples against S.mutans.
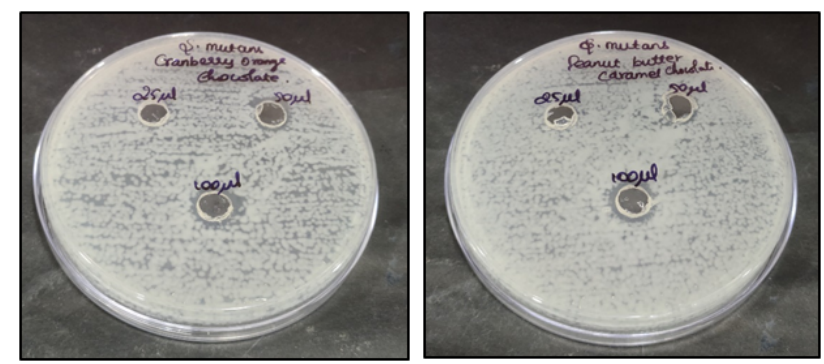

Figure 6. Antioxidant activity of probiotics from Peanut butter caramel probiotic chocolate.
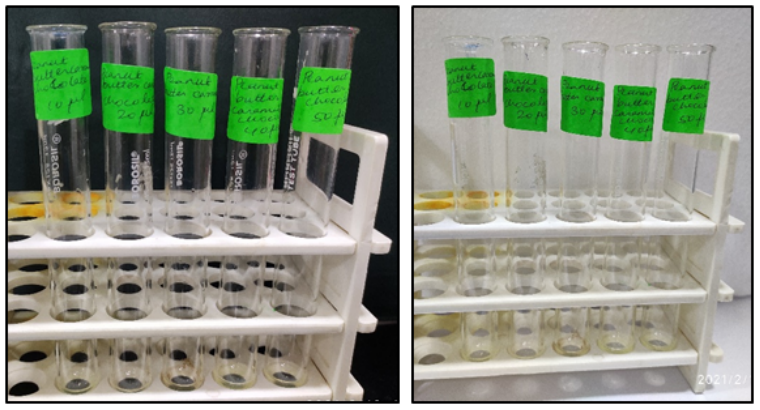

Figure 7. Antioxidant activity of probiotics from Cranberry orange probiotic chocolate.
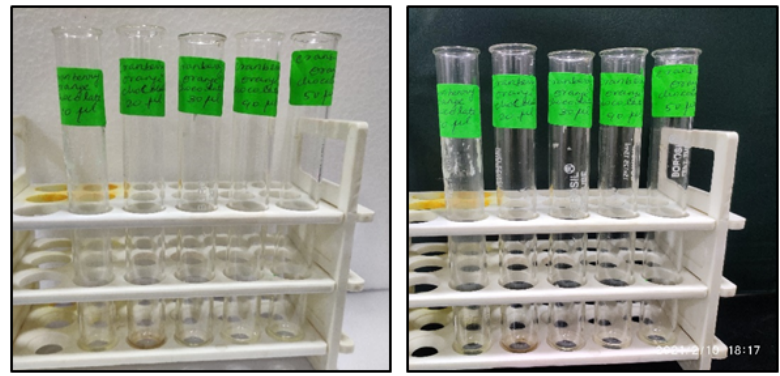
Graph 1. Antimicrobial activity of the samples against S. mutans.

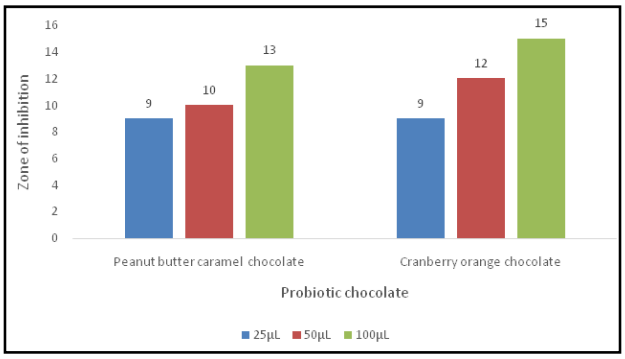

Graph 2. Antioxidant activity of both the samples.

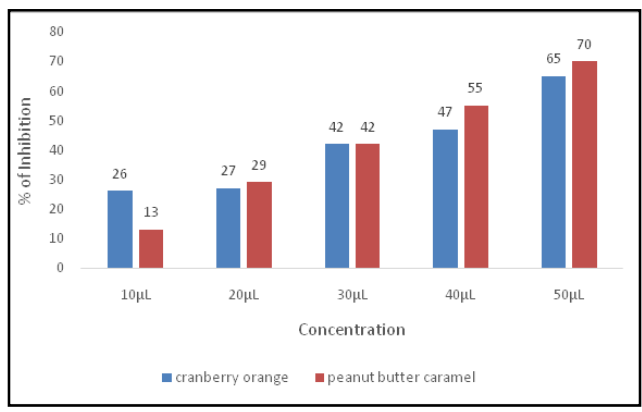

siderable value [34-36]. Probiotics are already incorporated into a wide range of dairy products or fruit juice. Another way to increase the efficacy of a probiotic bacteria would be to use a food matrix which naturally contains a higher content of ingredients with protective properties. As the lipid fraction of cocoa butter was shown to be protective for bifidobacterial [37].

In a study conducted by S.Possemiers et al, association of a chocolate coating with microencapsulated probiotic strains have been proved to be an excellent solution to protect them from environmental stress conditions [38]. Due to this, it has been attempted to be a carrier in many ways for symbiotic activity [39, 40].

In our study, we have evaluated the anti microbial activity of probiotic chocolate against the common oral pathogen S.mutans. . Diseases such as dental caries and periodontal disease are directly linked to oral microbiota [42]. Streptococcus mutans is the often implicated initiator and plaque-resident bacterium, that begins demineralization and the metabolism of simple carbohydrates and produces a by-product which paves the way for tissue loss and further bacterial action $[42,43]$. It initiates the biofilm formation by its adherence and accumulation on the tooth surface which is promoted by its synthesis of insoluble, extracellular polysaccharides. It also produces various bacteriocins that kill other bacteria, as it has a high efficiency in catabolizing carbohydrates and producing acids, and the ability to tolerate low $\mathrm{pH}$ [44].

Literature has shown that probiotic bacteria are not only associated with intestinal microbiota but it can also affect oral health, mucin production, competition with other flora and mucosal adherence. $[45,46]$.

Chocolate might be more or less responsible for tooth decay than any other carbohydrate containing foods such as bread, raisins, crackers, and fruit. However, only chocolate which is usually consumed as milk chocolate, candy bars contains large amount of sugar and complex carbohydrates and causes tooth decay and might inhibit the effect of antibacterial agents [47].
S. mutans being the arch enemy in thecaries development, more efforts have been directed towards inhibiting the known mechanisms of caries development such as; use of antimicrobial agents, fluorides, polyphenols to reduce biofilm and acid production done by S.mutans [46]. In our study, both the samples had antimicrobial activity. Similar findings were found in few more studies too[38, 46-48].

Chocolate has been used in antioxidant activity incorporating it with nanoparticles or probiotics. Our study also proved that probiotic chocolate had antioxidant activity. Similar findings were also found in studies conducted by Abd El-Moneim M.R. Afif et al and Dorota Najgebauer-Lejko et al [49, 50].

\section{Conclusion}

In our study, both the samples of probiotic chocolate exhibited antimicrobial and antioxidant properties. Cranberry orange exhibited more antibiotic activity and peanut butter caramel had more antioxidant potential at higher concentrations.

However, different stains of probiotic bacteria should be incorporated and tested invitro for their further potential before in vivo trials and commercial use

\section{References}

[1]. ANDRAE-NIGHTINGALE LM, LEE SY, Engeseth NJ. Textural changes in chocolate characterized by instrumental and sensory techniques. Journal of Texture Studies. 2009 Aug;40(4):427-44.

[2]. Afoakwa EO. Chocolate science and technology. Oxford: Wiley-Blackwell; 2010 Feb 2.

[3]. El-Kalyoubi M, Khallaf MF, Abdelrashid A, Mostafa EM. Quality characteristics of chocolate-Containing some fat replacer. Annals of Agricultural Sciences. 2011 Dec 1;56(2):89-96.

[4]. Rezende NV, Benassi MT, Vissotto FZ, Augusto PP, Grossmann MV. Mixture design applied for the partial replacement of fat with fibre in sucrose-free chocolates. LWT-Food Science and Technology. 2015 Jun 1;62(1):598-604.

[5]. Konar N, Toker OS, Oba S, Sagdic O. Improving functionality of chocolate: A review on probiotic, prebiotic, and/or synbiotic characteristics. Trends in Food Science \& Technology. 2016 Mar 1;49:35-44.

[6]. Halsted $\mathrm{CH}$. Dietary supplements and functional foods: 2 sides of a coin? 
Am J Clin Nutr. 2003 Apr;77(4 Suppl):1001S-1007S. Pubmed PMID: 12663307.

[7]. Boylston TD, Vinderola CG, Ghoddusi HB, Reinheimer JA. Incorporation of bifidobacteria into cheeses: challenges and rewards. International Dairy Journal. 2004 May 1;14(5):375-87.

[8]. Ferreira CL, Teshima E. Prebióticos, estratégia dietética para a manutenção da microbiota colônica desejável. Biotecnologia Ciencia \& Desenvolvimento. 2000 Sep;3:22-5.

[9]. FAO/WHO. Evaluation of health and nutritional properties of probiotics in food including powder milk with live lactic acid bacteria. Report of a joint FAO/WHO expert consultation, Co'rdoba, Argentina. 2001

[10]. Sanders ME. Probiotics: considerations for human health. Nutr Rev. 2003 Mar;61(3):91-9. Pubmed PMID: 12723641.

[11]. Ouwehand AC, Salminen S, Isolauri E. Probiotics: an overview of beneficial effects. Antonie Van Leeuwenhoek. 2002 Aug;82(1-4):279-89. Pubmed PMID: 12369194

[12]. Isolauri E. The role of probiotics in paediatrics. Current Paediatrics. 2004 Apr 1;14(2):104-9.

[13]. Heenan CN, Adams MC, Hosken RW, Fleet GH. Survival and sensory acceptability of probiotic microorganisms in a nonfermented frozen vegetarian dessert. LWT-Food Science and Technology. 2004 Jun 1;37(4):461-6.

[14]. Roberfroid M. Functional food concept and its application to prebiotics. Dig Liver Dis. 2002 Sep;34 Suppl 2:S105-10. Pubmed PMID: 12408452.

[15]. Bengmark S, García de Lorenzo A, Culebras JM. Use of pro-, pre- and synbiotics in the ICU--future options. Nutr Hosp. 2001 Nov-Dec;16(6):239-56. Pubmed PMID: 11840588.

[16]. Gibson GR. Dietary modulation of the human gut microflora using the prebiotics oligofructose and inulin. J Nutr. 1999 Jul;129(7 Suppl):1438S41S. Pubmed PMID: 10395616.

[17]. Schrezenmeir J, de Vrese M. Probiotics, prebiotics, and synbiotics--approaching a definition. Am J Clin Nutr. 2001 Feb;73(2 Suppl):361S-364S. Pubmed PMID: 11157342

[18]. Bielecka M, Biedrzycka E, Majkowska A. Selection of probiotics and prebiotics for synbiotics and confirmation of their in vivo effectiveness. Food Research International. 2002 Jan 1;35(2-3):125-31.

[19]. Pires MH. Sobremesas lácteas aeradas: sistemas de estabilizaçao e tecnologia de aeraçao. Food Ingredients. 2004;6(31):74-7.

[20]. Early R, editor. Technology of dairy products. Springer Science \& Business Media; 1998.

[21]. Khanafari A, HOSSEINI PS, TAJABADI EM. Investigation of probiotic chocolate effect on Streptococcus mutans growth inhibition.

[22]. Oliveira D, Antúnez L, Giménez A, Castura JC, Deliza R, Ares G. Sugar reduction in probiotic chocolate-flavored milk: Impact on dynamic sensory profile and liking. Food Res Int. 2015 Sep;75:148-156. Pubmed PMID: 28454942.

[23]. Rouhi M, Mohammadi R, Mortazavian AM, Sarlak Z. Combined effects of replacement of sucrose with d-tagatose and addition of different probiotic strains on quality characteristics of chocolate milk. Dairy Science \& Technology. 2015 Mar 1;95(2):115-33.

[24]. Kemsawasd V, Chaikham P, Rattanasena P. Survival of immobilized probiotics in chocolate during storage and with an in vitro gastrointestinal model. Food Biosci. 2016; 16; 37-43.

[25]. Silva MP, Tulini FL, Marinho JF, Mazzocato MC, De Martinis EC, Luccas $\mathrm{V}$, et al. Semisweet chocolate as a vehicle for the probiotics Lactobacillus acidophilus LA3 and Bifidobacterium animalis subsp. lactis BLC1: Evaluation of chocolate stability and probiotic survival under in vitro simulated gastrointestinal conditions. LWT. 2017 Jan 1;75:640-7.

[26]. Gadhiya D, Shah NP, Patel AR, Prajapati JB. Preparation and shelf life study of probiotic chocolate manufactured using Lactobacillus helveticus MTCC 5463. Acta Alimentaria. 2018 Sep;47(3):350-8.

[27]. Mirković M, Seratlić S, Kilcawley K, Mannion D, Mirković N, Radulović Z. The Sensory Quality and Volatile Profile of Dark Chocolate Enriched with Encapsulated Probiotic Lactobacillus plantarum Bacteria. Sensors (Basel). 2018 Aug 6;18(8):2570. Pubmed PMID: 30082608

[28]. Peres J, Esmerino E, da Silva AL, Racowski I, Bolini H. Sensory Profile, Drivers of Liking, and Influence of Information on the Acceptance of LowCalorie Synbiotic and Probiotic Chocolate Ice Cream. J Food Sci. 2018
May;83(5):1350-1359. Pubmed PMID: 29660810.

[29]. Eor JY, Tan PL, Lim SM, Choi DH, Yoon SM, Yang SY, et al. Laxative effect of probiotic chocolate on loperamide-induced constipation in rats. Food Res Int. 2019 Feb;116:1173-1182. Pubmed PMID: 30716903.

[30]. Chellapa LR, Shanmugam R, Indiran MA, Samuel SR. Biogenic nanoselenium synthesis, its antimicrobial, antioxidant activity and toxicity. Bioinspired, Biomimetic and Nanobiomaterials. 2020 Sep 9;9(3):184-9.

[31]. Lleó MM, Tafi MC, Canepari P. Nonculturable Enterococcus faecalis cells are metabolically active and capable of resuming active growth. Syst Appl Microbiol. 1998 Aug;21(3):333-9. Pubmed PMID: 9841123.

[32]. Mir-Hoseini M. Study of effect of nisin and producer bacteria of nisin on Listeria monocytogenes and Bacillus cereus. Isfahan: University of Isfahan. 2004.

[33]. Anal AK, Singh H. Recent advances in microencapsulation of probiotics for industrial applications and targeted delivery. Trends in Food Science \& Technology. 2007 May 1;18(5):240-51.

[34]. Picot A, Lacroix C. Production of multiphase water-insoluble microcapsules for cell microencapsulation using an emulsification/spray-drying technology. Journal of food science. 2003 Nov;68(9):2693-700.

[35]. Picot A, Lacroix C. Encapsulation of bifidobacteria in whey protein-based microcapsules and survival in simulated gastrointestinal conditions and in yoghurt. International dairy journal. 2004 Jun 1;14(6):505-15.

[36]. Hou RC, Lin MY, Wang MM, Tzen JT. Increase of viability of entrapped cells of Lactobacillus delbrueckii ssp. bulgaricus in artificial sesame oil emulsions. J Dairy Sci. 2003 Feb;86(2):424-8. Pubmed PMID: 12647948.

[37]. Lahtinen SJ, Ouwehand AC, Salminen SJ, Forssell P, Myllärinen P. Effect of starch- and lipid-based encapsulation on the culturability of two Bifidobacterium longum strains. Lett Appl Microbiol. 2007 May;44(5):500-5. Pubmed PMID: 17451516.

[38]. Possemiers S, Marzorati M, Verstraete W, Van de Wiele T. Bacteria and chocolate: a successful combination for probiotic delivery. Int J Food Microbiol. 2010 Jun 30;141(1-2):97-103. Pubmed PMID: 20452073.

[39]. Halsted CH. Dietary supplements and functional foods: 2 sides of a coin? Am J Clin Nutr. 2003 Apr;77(4 Suppl):1001S-1007S. Pubmed PMID: 12663307.

[40]. Aragon-Alegro LC, Alegro JH, Cardarelli HR, Chiu MC, Saad SM. Potentially probiotic and synbiotic chocolate mousse. LWT-Food Science and technology. 2007 May 1;40(4):669-75.

[41]. Stamatova I. Probiotic activity of Lactobacillus delbrueckii subsp. bulgaricus in the oral cavity.

[42]. Forssten SD, Björklund M, Ouwehand AC. Streptococcus mutans, caries and simulation models. Nutrients. 2010 Mar;2(3):290-8. Pubmed PMID: 22254021.

[43]. Simon L. The role of Streptococcus mutans and oral ecology in the formation of dental caries.

[44]. Khanafari A, HOSSEINI PS, TAJABADI EM. Investigation of probiotic chocolate effect on Streptococcus mutans growth inhibition.

[45]. Reddy JJ, Sampathkumar N, Aradhya S. Probiotics in dentistry: review of the current status. Archives of Oral Research. 2010 Nov 29;6(3).

[46]. Haukioja A, Loimaranta V, Tenovuo J. Probiotic bacteria affect the composition of salivary pellicle and streptococcal adhesion in vitro. Oral Microbiol Immunol. 2008 Aug;23(4):336-43. Pubmed PMID: 18582334.

[47]. Żyżelewicz D, Nebesny E, Motyl I, Libudzisz Z. Effect of milk chocolate supplementation with lyophilised lactobacillus cells on its attributes. Czech Journal of Food Sciences. 2010 Oct 14;28(5):392-406.

[48]. Dakshinamoorthy M, Subramanian MO, Padmavathi KE, Mahalakshmi KR, Arumugam KA, Paramasivam V. Effect of Probiotic Chocolate in the Reduction of Streptococcus Mutans Count. Biomedical \& Pharmacology Journal. 2016;9(3):1073-8.

[49]. Afify AE, Romeilah RM, Sultan SI, Hussein MM. ANTIOXIDANT ACTIVITY AND BIOLOGICAL EVALUATIONS OF PROBIOTIC BACTERIA STRAINS. International Journal of Academic Research. 2012 Nov $1 ; 4(6)$.

[50]. Najgebauer-Lejko D, Sady M. Estimation of the antioxidant activity of the commercially available fermented milks. Acta Sci Pol Technol Aliment. 2015 Oct-Dec;14(4):387-396. Pubmed PMID: 28068044. 